\title{
Dual Luminescence and Long-Lived Charge-Separated States in Donor-Acceptor Assemblies Based on Tetrathiafulvalene-Fused Ruthenium(II)-Polypyridine Complexes
}

\author{
Claudia Leiggener ${ }^{a}$, Nathalie Dupont ${ }^{a}$, Shi-Xia Liu ${ }^{b}$, Christine Goze $^{b}$, Silvio Decurtins ${ }^{b}$, \\ Elvira Breitler ${ }^{b}$, and Andreas Hauser ${ }^{\star a}$
}

\begin{abstract}
The creation of long-lived charge-separated states in donor-acceptor assemblies has been the goal of many studies aimed at mimicking the primary processes in photosynthesis. Here we present such assemblies based on tetrathiafulvalene (TTF) as electron donor and a dipyridophenazine (dppz) unit as electron acceptor in the form of a fused ligand (TTF-dppz) coordinated to ruthenium(II) via the dipyrido coordination site and with 2,2'bipyridine (bpy) as auxiliary ligand, namely $\left.\left[R u(b p y)_{3-x}(T T F-d p p z)\right]_{x}\right]^{2+}(x=1-3)$. For $x=2$, irradiation into the metal to $\mathrm{dppz}$ charge transfer transition results in electron transfer from TTF to ruthenium, thus creating a charge-separated state best described by $\left[\left(T_{T F}^{+}-d p p z\right) R u\left(d p p z^{-}-T T F\right)(b p y)\right]^{2+}$ with a lifetime of $2.5 \mu$ s in dichloromethane.
\end{abstract}

Keywords: Charge-separated states · Intraligand charge transfer · Metal-ligand-charge-transfer . Ruthenium(II)-polypyridine complexes · Tetrathiafulvalene

\section{Introduction}

Molecular photochemistry and photophysics play an important role both in modern technologies such as lighting,,$^{[1]}$ laser applications, electroluminescent materials, ${ }^{[2]}$ sensing devices, ${ }^{[3]}$ and solar energy conversion, ${ }^{[4]}$ as well as in nature as for instance photosynthesis. ${ }^{[5]}$ The complex sequence of events can very often be broken down into elementary steps. Of course the first

\footnotetext{
${ }^{\star}$ Correspondence: Prof. Dr A. Hauser ${ }^{a}$

Tel.: +41213796559

Fax: + 41213796103

E-mail: andreas.hauser@unige.ch

aDépartement de Chimie Physique

Université de Genève

30 Quai Ernest-Ansermet

$\mathrm{CH}-1211$ Genève 4

bepartement für Chemie und Biochemie

Universität Bern

Freiestrasse 3

$\mathrm{CH}-3012$ Bern
}

step is always given by the absorption of a photon, which promotes the chromophore to an electronically and often vibrationally excited state. This initially excited state is most often extremely short-lived, and the system decays via vibrational relaxation, internal conversion, intersystem crossing, luminescence, and energy and electron transfer back to the ground state or via some chemical reaction to a given photochemical product.

A key issue of photophysics and photochemistry is the creation of long-lived charge-separated states using so-called donor-acceptor (DA) assemblies, in which the excitation of either the donor to $\mathrm{D}^{*} \mathrm{~A}$ or the acceptor to $\mathrm{DA}^{*}$ is followed by the transfer of an electron from $D$ to $A$ to form a state best described by $\mathrm{D}^{+} \mathrm{A}^{-}$. As an extension of the simple dyad, the donor and the acceptor may be linked by a photophysically active bridge to afford the triad DBA. In this case, the excitation of the bridge to $\mathrm{DB}^{*} \mathrm{~A}$ results in double electron transfer, namely from the HOMO of D to the SOMO-1 of $\mathrm{B}^{*}$ and from the SOMO of B* to the LUMO of $\mathrm{A}$, thus forming a species of the form $\mathrm{D}^{+} \mathrm{BA}^{-}$, which in general has a longer lifetime of the charge-separated state than that in the corresponding dyad due to the weaker electronic coupling between D and A. Such triads, composed of tetrathiafulvalene, porphyrins and fullerenes have been successfully used in the creation of artificial photosynthetic systems. ${ }^{[6]}$

Tertrathiafulvalene derivatives, on the one hand, constitute a class of versatile electron donors for a number of interesting applications, ${ }^{[7]}$ in fields such as molecular electronics ${ }^{[8]}$ and in organic conductors and superconductors. ${ }^{[9]}$ Of particular interest in the context of this paper is that they are known to quench the luminescence of almost any chromophore in their vicinity through reductive electron transfer quenching. ${ }^{[10]}$ Ruthenium(II) polypyridine complexes, on the other hand, are known not only for the luminescence from metal-to-ligand-chargetransfer (MLCT) states but also for their use as sensitizers for light-induced electron transfer in solar energy conversion. ${ }^{[11]}$ Usually the incorporation of tetrathiafulvalene derivatives into ruthenium(II) complexes results in the above-mentioned intramolecular electron transfer quenching of the ruthenium complex based luminescence. ${ }^{[12]}$ However, in the systems investigated to date, the resulting charge-separated states were not very long-lived, because the tetrathiafulvalene was linked flexibly to the 
ruthenium(II) chromophore, and thus the average spatial separation between the units is too small.

In an attempt to sequentially assemble a rigidly bridged donor acceptor triad combining a tetrathiafulvalene derivative with a ruthenium(II) polypyridile complex, we first synthesized the two ligands shown in Fig. 1a, where 4',5'-bis-(propylthio)-substituted tetrathiafulvalene (TTF) is fused to two different dipyridophenazine units, namely dipyrido[3,2-a:2',3'-c]phenazine $(d p p z)^{[13]}$ and dipyrido[2,3-a:3',2'-c]phenazine (dppz').

With their bidentate diimine binding sites the two ligands can easily be coordinated to a number of transition metal ions. Of particular interest within the context of this special issue of CHIMIA is coordination to spectroscopically and photophysically active transition-metal ions such as ruthenium(II). Fig. 1b depicts the series of mononuclear complexes with 1,2 or 3 TTFdppz ligands, namely $\left[\mathrm{Ru}(\mathrm{bpy})_{3-\mathrm{x}}(\mathrm{TTF}-\right.$ dppz $\left.)_{\mathrm{x}}\right]^{2+}\left(\right.$ bpy $=2,2^{\prime}$-bipyridine, $\mathrm{x}=$ $1-3)^{[14]}$ as well as the dinuclear complex $\left[\left\{\mathrm{Ru}(\mathrm{bpy})_{2}\right\}_{2}(\mu-\mathrm{TTF}-\mathrm{dppz})\right]^{4+}$.

In this paper, we shall begin our discussion on the spectroscopic and photophysical properties of the free ligands, which are quite unique and interesting in their own right. We shall then proceed to examine the effect of their coordination to innocent zinc(II) ions before turning to the main subject of our contribution, namely the discussion of the luminescence properties of the ruthenium complexes and the creation of long-lived charge-separated states, in which the TTF unit acts as electron donor.

\section{Results and Discussion}

\subsection{The Free Ligands}

Fig. 2 shows the absorption spectra of the two ligands, TTF-dppz and TTF-dppz', in $\mathrm{CH}_{2} \mathrm{Cl}_{2}$. For reference the absorption spectra of dppz and free TTF are included. The spectra of the two fused ligands are very similar to each other, but they are not at all equal to the sum of the two reference spectra. Indeed, there is an additional band centered at $18500 \mathrm{~cm}^{-1}$ with an oscillator strength $\mathrm{f} \approx 0.17$. Even though neutral TTF is known to quench all luminescence by electron transfer, both compounds emit quite strongly in the near infrared (Fig. 2). The exact position of the emission band and the quantum yield depend on the solvent, ranging from $11600 \mathrm{~cm}^{-1}$ and $0.13 \%$, respectively for DMF to $16100 \mathrm{~cm}^{-1}$ and $7.6 \%$, respectively, for cyclohexane. The corresponding values in $\mathrm{CH}_{2} \mathrm{Cl}_{2}$ are 12200 $\mathrm{cm}^{-1}$ and $1 \%$, which together with the experimental luminescence lifetime of $0.4 \mathrm{~ns}$ in the same solvent give a radiative lifetime of the emitting state of $\sim 40 \mathrm{~ns}$. Thus the emission can be clearly identified as the

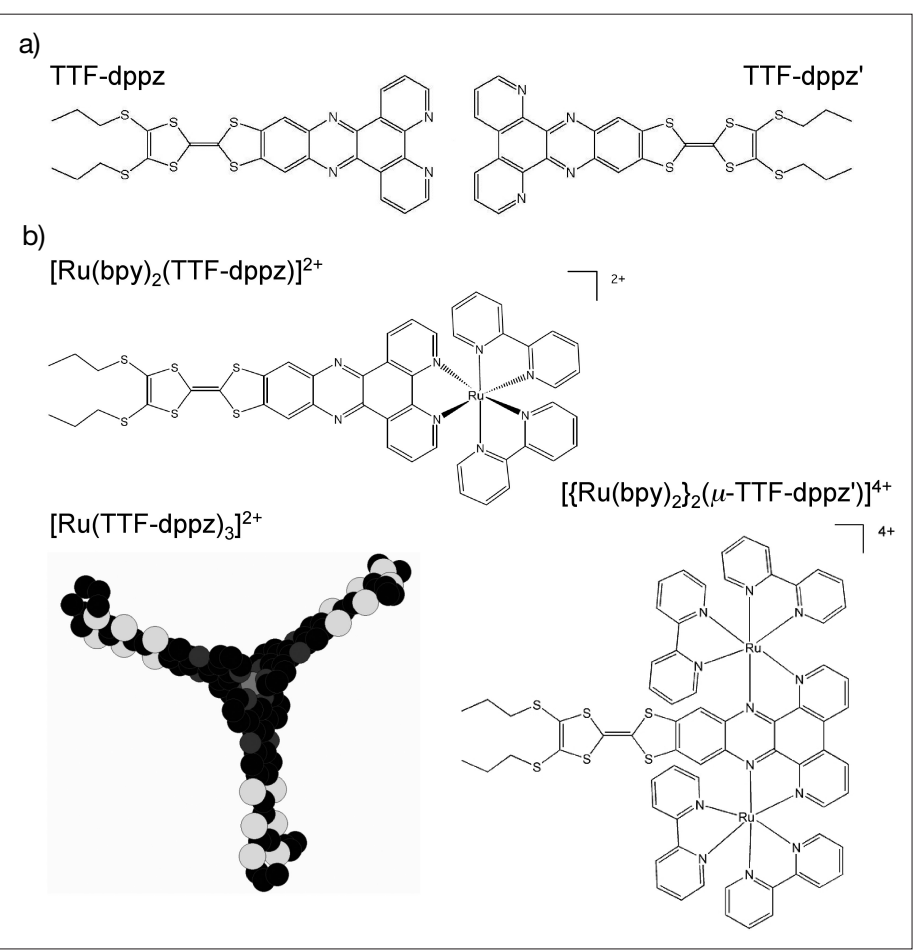

Fig. 1. a) The ligands TTF-dppz and TTF-dppz'. b) The mononuclear complexes $\left[R u(b p y)_{2}(T T F-d p p z)\right]^{2+}$ and $\left[R u(T T F-d p p z)_{3}\right]^{2+}$, and the dinuclear complex $\left[\left\{R u(b p y)_{2}\right\}_{2}\left(T T F-d p p z^{\prime}\right)\right]^{4+}$.

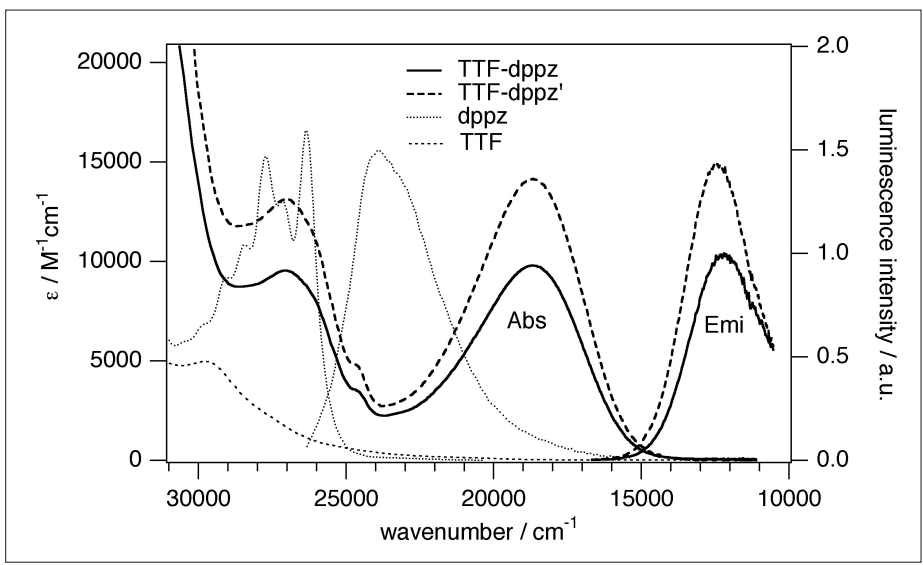

Fig. 2. Absorption and emission spectra of TTF-dppz (__ ) and TTF-dppz' (---) in $\mathrm{CH}_{2} \mathrm{Cl}_{2}$ as well as the corresponding spectra of the reference compounds dppz (...) and TTF (- - -). TTF shows no emission.

Stokes-shifted fluorescence of the corresponding absorption band at $18500 \mathrm{~cm}^{-1}$.

The Lippert-Mataga plot of the variation of the Stokes shift as a function of the dielectric constant of the solvent gives a change in dipole moment from the ground state to the excited state of $\sim 18$ Debye. Even though the Lippart-Mataga treatment tends to overestimate the changes in dipole moment associated with a spectroscopic transition, this is a clear indication that the said transition is an intraligand charge transfer (ILCT) transition corresponding essentially to a transfer of charge from the HOMO centered on the TTF moiety to the LUMO centered on the dppz unit. This assignment is corroborated by computa- tional results based on density functional theory. Thus, in the fused donor-acceptor compounds TTF-dppz and TTF-dppz', the ILCT luminescence is not quenched by TTF because TTF actively participates in the lowest energy spectroscopic transition, the lowest energy singlet state being best described by $\mathrm{TTF}^{\delta+}-\mathrm{dppz}^{\delta-}$. Electrochemical data of TTF-dppz support this conclusion, as the difference in redox potentials of $2.2 \mathrm{~V}$ between the first oxidation of TTF and the first reduction of dppz is very close to the zero-point energy of the ILCT state of $\sim 16000 \mathrm{~cm}^{-1}$ as estimated from the crossing point of the absorption and the emission spectrum. For more details see ref. [13]. 


\subsection{Coordination to Innocent Transition Metal lons}

Both TTF-dppz and TTF-dppz' can be coordinated to metal ions. This has an immediate impact on the position of the ILCT band. The coordination to positively charged metal ions increases the acceptor properties of the dppz and dppz' moieties and consequently the ILCT bands shift to lower energies, as borne out by the absorption spectra shown in Fig. 3. Upon addition of $\mathrm{Zn}^{2+}$ to a solution of TTF-dppz, the shift is $\sim 2000$ $\mathrm{cm}^{-1}$. The full shift is reached upon addition of little more than one third mole equivalents of $\mathrm{Zn}^{2+}$, indicating that initially more than one TTF-dppz ligand is coordinated to one $\mathrm{Zn}^{2+}$ ion. This, in turn, indicates that the shift is essentially due to electrostatic interactions, and, indeed, addition of a weak acid to a solution of TTF-dppz has exactly the same effect. For TTF-dppz' with potentially two coordination sites the shift occurs in two distinct steps. Addition of about one half of an equivalent again results in a shift this time of $\sim 3000 \mathrm{~cm}^{-1}$. Further addition of $\mathrm{Zn}^{2+}$ enhances the effect and results in a further red shift of $\sim 2000 \mathrm{~cm}^{-1}$.

In addition, the mononuclear complex with TTF-dppz also shows the ILCT luminescence, red-shifted by the same 2000 $\mathrm{cm}^{-1}$ as the absorption and with a slightly smaller quantum yield. The reduction of the quantum yield is, however, not due to an active quenching by $\mathrm{Zn}^{2+}$, but merely due to the expected increase in the non-radiative multiphonon relaxation according to the energy gap law.

\subsection{Coordination to Ruthenium(II)}

Fig. 4a shows the absorption and emission spectra of $\left[\mathrm{Ru}(\mathrm{bpy})_{2}(\mathrm{TTF}-\mathrm{dppz})\right]^{2+}$ in direct comparison to those of the reference complexes $\left[\mathrm{Ru}(\mathrm{bpy})_{2}(\mathrm{dppz})\right]^{2+}$ and $\left[\mathrm{Ru}(\mathrm{bpy})_{3}\right]^{2+}$. The reference complexes both have intense absorption bands at 35000 and at $22000 \mathrm{~cm}^{-1}$, which have been attributed to $\pi \pi^{*}$ transitions on the ligands and to the spin-allowed metal-ligand-charge transfer $\left({ }^{1} \mathrm{MLCT}\right)$ transition from the metal to bpy and dppz, respectively. Both show luminescence centered at $16000 \mathrm{~cm}^{-1}$ originating from the corresponding ${ }^{3} \mathrm{MLCT}$ states. The absorption spectrum of [Ru(bpy) ${ }_{2}$ (TTF-dp$\mathrm{pz})]^{2+}$ shows additional features in the form of a shoulder at 30000 and a strong band at $16000 \mathrm{~cm}^{-1}$, which can be attributed to a $\pi \pi^{*}$ transition and the red-shifted ILCT transition of TTF-dppz.

Coordination of more than one TTFdppz ligand to one ruthenium(II) ion in the series $\left[\mathrm{Ru}(\mathrm{bpy})_{3-\mathrm{x}}(\mathrm{TTF}-\mathrm{dppz})_{\mathrm{x}}\right]^{2+}$, $\mathrm{x}$ $=1-3$, results in a linear increase of the molar absorption of the TTF-dppz ILCT band with respect to the concentration of the complex, as shown in Fig. 4b. For $x$ $=3$, the low-energy shoulder on the ILCT

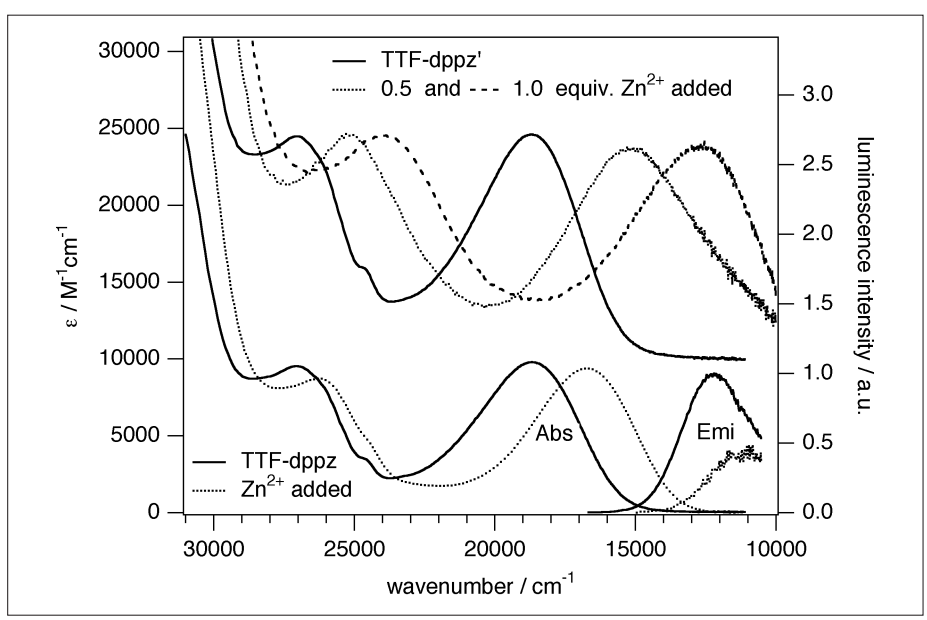

Fig. 3. The effect on absorption and emission spectra of TTF-dppz and TTF-dppz' in $\mathrm{CH}_{2} \mathrm{Cl}_{2}$ upon addition of $\mathrm{Zn}^{2+}$ to the solution: top TTF-dppz' (_), TTF.dppz' +0.5 equiv. $\mathrm{Zn}^{2+}$ (...), TTF- ddpz' +1.0 equiv. $\mathrm{Zn}^{2+}(---)$; bottom TTF-dppz (_), TTF-dppz +0.5 equiv. $\mathrm{Zn}^{2+}(\ldots$.$) ; absorption left,$ emission right.

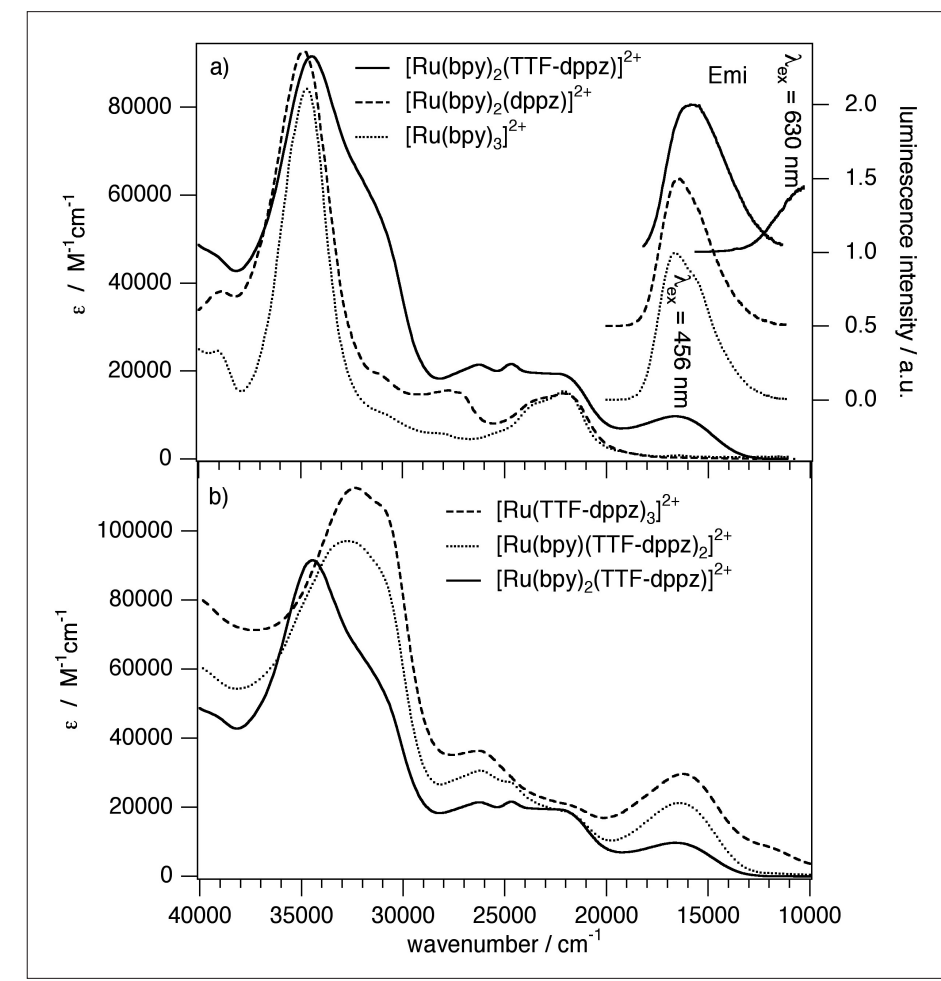

Fig. 4. a) Absorption and emission spectra of $\left[R u(b p y)_{2}(T T F-d p p z)\right]^{2+}$, $\left[\mathrm{Ru}(\mathrm{bpy})_{2}(\mathrm{dppz})\right]^{2+}$ and $\left[\mathrm{Ru}(\mathrm{bpy})_{3}\right]^{2+}$ in degassed $\mathrm{CH}_{2} \mathrm{Cl}_{2}$, b) absorption spectra of $\left[\mathrm{Ru}(\mathrm{bpy})_{2}(\mathrm{TTF}-\mathrm{dppz})\right]^{2+},\left[\mathrm{Ru}(\mathrm{bpy})(\mathrm{TTF}-\mathrm{dpp} \mathrm{z})_{2}\right]^{2+}$ and $[\mathrm{Ru}(\mathrm{TTF}-$ dppz) $\left.]_{3}\right]^{2+}$ in $\mathrm{CH}_{2} \mathrm{Cl}_{2}$.

band indicates a non-negligible exciton splitting.

Whereas the complex with one TTFdppz ligand, $\left[\mathrm{Ru}(\mathrm{bpy})_{2}(\mathrm{TTF}-\mathrm{dppz})\right]^{2+}$, shows unusual dual luminescence behavior both from the ILCT state and the ${ }^{3}$ MLCT state, the complexes with more than one TTF-dppz ligand show only the weak luminescence of the ILCT state. This is to be discussed in more detail below.

The absorption spectrum of the dinuclear complex $\left[\left\{\mathrm{Ru}(\mathrm{bpy})_{2}\right\}_{2}(\mu-\mathrm{TTF}-\mathrm{dppz})\right]^{4+}$ displayed in Fig. 5 together with the absorption spectra of $\left[\left\{\mathrm{Ru}(\mathrm{bpy})_{2}\right\}_{2}(\mathrm{dppz})\right]^{4+}$, $\left[\mathrm{Ru}(\mathrm{bpy})_{2}(\mathrm{dppz})\right]^{2+}$ and $\left[\mathrm{Ru}(\mathrm{bpy})_{2}\right.$ (TTFdppz) $]^{2+}$ for direct comparison, shows the ILCT band now shifted even further into the red with the maximum at $12000 \mathrm{~cm}^{-1}$. In contrast to the mononuclear complex with a head-on coordination for which the $\mathrm{Ru} \rightarrow$ bpy and $\mathrm{Ru} \rightarrow \mathrm{dppz}{ }^{1} \mathrm{MLCT}$ transitions are very close in energy, the dinuclear complex with a side-on coordination to dppz' displays two distinct MLCT bands, namely 


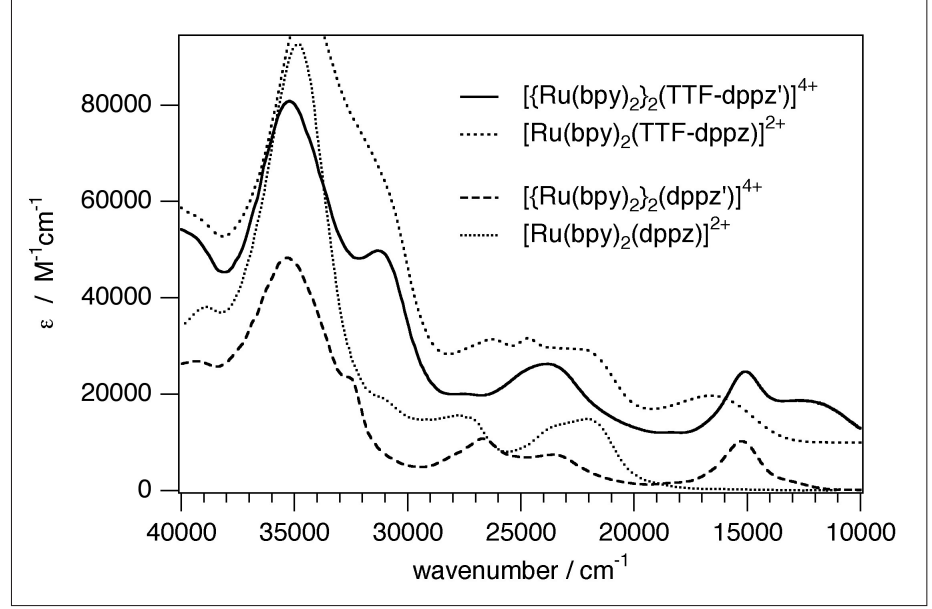

Fig. 5. Absorption spectra of $\left[\left\{R u(b p y)_{2}\right\}_{2}(d p p z ')\right]^{4+}$ and $\left[\left\{R u(b p y)_{2}\right\}_{2}(\mu-T T F-\right.$ $\mathrm{dppz})]^{4+}$ in $\mathrm{CH}_{2} \mathrm{Cl}_{2}$. For direct comparison the spectra of $\left[\mathrm{Ru}(\mathrm{bpy})_{2}(\mathrm{dppz})\right]^{2+}$ and $\left[\mathrm{Ru}(\mathrm{bpy})_{2}(\mathrm{TTF}-\mathrm{dppz})\right]^{2+}$ from Fig. 4 are included.

at $15000 \mathrm{~cm}^{-1}$ corresponding to $\mathrm{Ru} \rightarrow \mathrm{dppz}$ $\mathrm{CT}$, and at $23500 \mathrm{~cm}^{-1}$ corresponding to $\mathrm{Ru} \rightarrow$ bpy $\mathrm{CT}$. The dinuclear complex shows no luminescence in the visible, and if there is any luminescence of the ILCT state in the NIR, its intensity is below the sensitivity of the available experimental set-up.

\subsection{Dual Luminescence and Long- lived Charge-separated States}

Similar to the coordination with $\mathrm{Zn}^{2+}$, $\left[\mathrm{Ru}(\mathrm{bpy})_{2}(\mathrm{TTF}-\mathrm{dppz})\right]^{2+}$ shows luminescence from the lowest energy ILCT state with a maximum at $\sim 10000 \mathrm{~cm}^{-1}$ upon irradiation at $16000 \mathrm{~cm}^{-1}$, that is selectively into the ILCT absorption. Most interestingly, irradiation into the ${ }^{1}$ MLCT band at 22000 $\mathrm{cm}^{-1}$ results in luminescence, which can be identified as ${ }^{3}$ MLCT luminescence from its position at $15300 \mathrm{~cm}^{-1}$ and the associated lifetime of $1040 \mathrm{~ns}$ (Fig. 4). On the other hand, the two complexes with more than one TTF-dppz ligand per metal ion only show the weak luminescence of the ILCT state. The behavior of the complexes with more than one TTF-dppz ligand is as expected, in so far as TTF quenches the ${ }^{3}$ MLCT luminescence of the ruthenium(II)-based chromophore via reductive electron transfer. So the key question is, why is the ${ }^{3}$ MLCT luminescence not likewise quenched by reductive electron transfer from the TTF unit in the case of the complex with only one TTF-dppz ligand? As mentioned above, in $\left[\mathrm{Ru}(\mathrm{bpy})_{2}(\mathrm{TTF}-\mathrm{dppz})\right]^{2+}$ the $\mathrm{Ru} \rightarrow$ bpy $\mathrm{CT}$ and the $\mathrm{Ru} \rightarrow$ dppz $\mathrm{CT}$ states are quite close in energy, so irradiation at $22000 \mathrm{~cm}^{-1}$ excites both states simultaneously. However, it is generally acknowledged that the MLCT state with the electron on dppz is lower in energy. ${ }^{[15]}$ Therefore, as depicted in Fig. 6a, the lowest energy ${ }^{3}$ MLCT state is best described as $\left[\mathrm{Ru}^{3+}(\mathrm{bpy})_{2}(\mathrm{TTF}-\right.$ $\left.\left.\mathrm{dppz}^{-}\right)\right]^{2+}$. Electron transfer quenching by the TTF unit would involve transfer of an

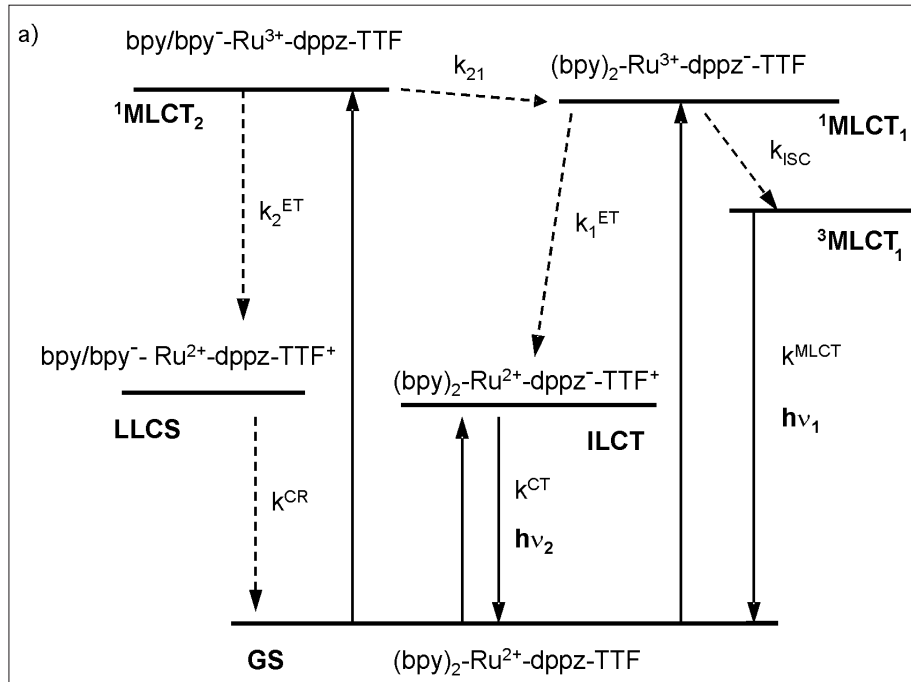

b)

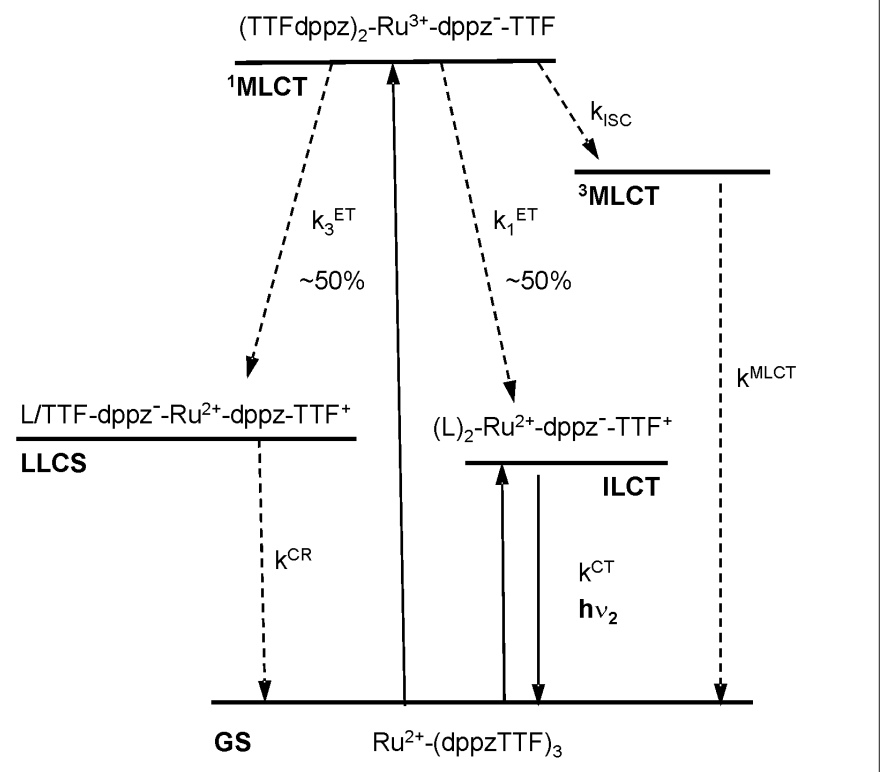

Fig. 6. Scheme of photophysical processes in a) $\left[\mathrm{Ru}(\mathrm{bpy})_{2}(\mathrm{TTF}-\mathrm{dppz})\right]^{2+}$ and b) $\left[R u(T T F-d p p z)_{3}\right]^{2+}$. L stands for the neutral TTF-dppz (adapted from ref. [14]).

electron from the TTF unit to the $\mathrm{Ru}^{3+}$, forming the ILCT state $\left[\mathrm{Ru}^{2+}(\mathrm{bpy})_{2}\left(\mathrm{TTF}^{+}-\right.\right.$ $\left.\left.\mathrm{dppz}^{-}\right)\right]^{2+}$. The driving force for this process is quite substantial, but in order for it to occur, the transferred electron would have to tunnel through the Coulomb barrier of the electron in the $\pi^{*}$ orbital localized on the dppz unit. This slows down the electron transfer process sufficiently for the intersystem crossing process from the initially excited ${ }^{1}$ MLCT state to the ${ }^{3}$ MLCT followed by ${ }^{3}$ MLCT luminescence to become competitive. In the complexes with more than one TTF-dppz ligand the situation is different, as shown for [Ru(TTFdppz $\left.)_{3}\right]^{2+}$ in Fig. 6b. The initially excited CT state may be described by $\left[\mathrm{Ru}^{3+}(\mathrm{TTF}-\right.$ $\left.\left.\mathrm{dppz}^{-}\right)(\mathrm{TTF}-\mathrm{dppz})_{2}\right]^{2+}$. In addition to intersystem crossing, electron transfer from a TTF unit other than the one for which the corresponding dppz unit is negatively charged is now competitive, resulting in a ligand-to-ligand charge separated (LLCS) state of the form $\left[\mathrm{Ru}^{2+}\left(\mathrm{TTF}-\mathrm{dppz}^{-}\right)\left(\mathrm{TTF}^{+}{ }_{-}\right.\right.$ dppz)(TTF-dppz) $]^{2+}$. This is borne out by the transient absorption spectrum of $\left[\mathrm{Ru}(\mathrm{TTF}-\mathrm{dppz})_{3}\right]^{2+}$ upon pulsed excitation at $22000 \mathrm{~cm}^{-1}$ shown in Fig. 7 together with the ground state absorption spectrum and the spectrum of the chemically oxidized species $\left[\mathrm{Ru}^{2+}(\mathrm{TTF}-\mathrm{dppz})_{2}\left(\mathrm{TTF}^{+}-\mathrm{dppz}\right)\right]^{3+}$. The absorption spectrum of the oxidized species shows a reduced absorption at the energy of the ILCT transition and a strong new absorption band at $12000 \mathrm{~cm}^{-1}$. The former indicates a loss in the intensity of the $\mathrm{TTF} \rightarrow$ dppz ILCT transition, the latter can be attributed to a dppz $\rightarrow \mathrm{TTF}^{+}$ILCT transition on the oxidized species, ${ }^{[13]}$ and thus constitutes a signature for the presence of a $\mathrm{TTF}^{+}$-dppz unit. Similarly, the transient difference spectrum shows a bleaching of the 


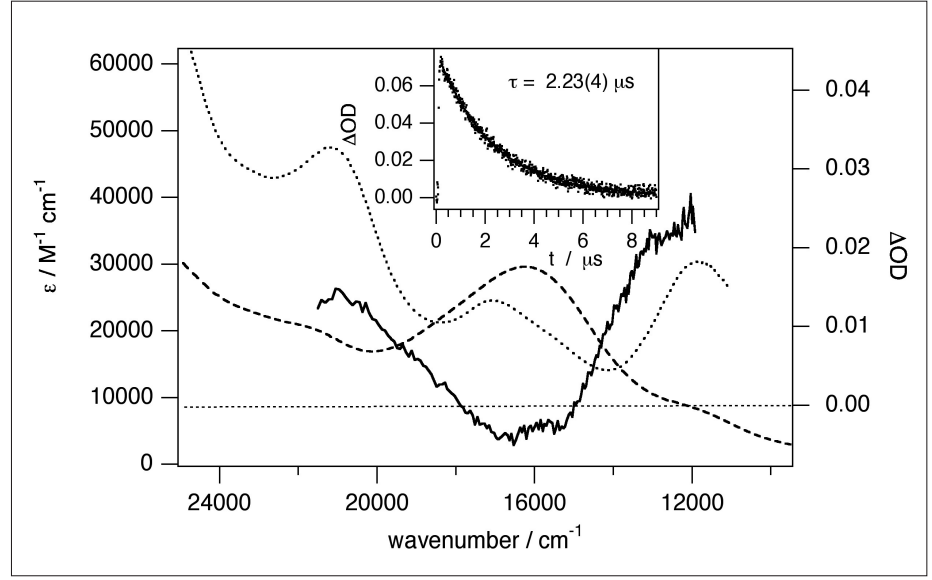

Fig. 7. Absorption spectrum of $\left[\mathrm{Ru}(T \mathrm{TTF}-\mathrm{dppz})_{3}\right]^{2+}$ in $\mathrm{CH}_{2} \mathrm{Cl}_{2}$ (----), the chemically oxidized form (....), and the transient difference absorption spectrum (_ upon pulsed irradiation at $16000 \mathrm{~cm}^{-1}$. Inset: decay of the transient state monitored at $12500 \mathrm{~cm}^{-1}$.

ILCT transition and an increased absorption characteristic for the $\mathrm{TTF}^{+}-\mathrm{dppz}$ unit, thus supporting the hypothesis of a fast formation of the LLCS state as a transient state. In fact, the transient spectra of all three complexes show these features, and thus in all three complexes such a LLCS state with a lifetime of $2.5 \mu \mathrm{s}$ is formed. As a result, the full schemes for the processes in all three complexes shown in Fig. 6a and b can be established, the one for [Ru(bpy)(TTF$\left.\mathrm{dppz})_{2}\right]^{2+}$ being a combination of the ones for $\left[\mathrm{Ru}(\mathrm{bpy})_{2}(\mathrm{TTF}-\mathrm{dppz})\right]^{2+}$ and $[\mathrm{Ru}(\mathrm{TTF}-$ $\left.\mathrm{dppz})_{3}\right]^{2+}$. Of course, for $\left[\mathrm{Ru}(\mathrm{bpy})_{2}(\mathrm{TTF}-\right.$ dppz) $]^{2+}$ the charge-separated state is preferentially formed upon excitation into the $\mathrm{Ru} \rightarrow$ bpy ${ }^{1} \mathrm{MLCT}$ absorption, and the electron is localized on one of the bpy ligands.

\section{Conclusions}

The creation of functional multi-component assemblies is one of the important goals of modern chemistry, and systems with long-lived charge-separated states at comparatively high energies are of particular interest for the discussion of solar energy conversion based on mimicking natural photosynthesis. In the rigid donor-acceptor assembly with a central ruthenium(II) ion coordinated by TTF-dppz, the TTF unit serves as electron donor to ruthenium with a formal charge of +3 upon irradiation into the MLCT bands. In the resulting chargeseparated state, both the auxiliary bipyridine ligand in the system with only one TTF-dppz ligand as well as the dppz unit of the TTF-dppz ligand itself in the system with more than one such ligand may serve as electron acceptors. The $\left[\mathrm{Ru}(\mathrm{bpy})_{2}\right.$ (TTF$\mathrm{dppz})]^{2+}$ complex, in addition, shows an unusual dual luminescence due to the fact that in the lowest energy MLCT state, the electron in the $\pi^{*}$ orbital of the dppz unit serves as Coulomb barrier for the electron transfer from TTF to ruthenium. The processes leading to the formation of the charge-separated states are very fast indeed and will require ultra-fast spectroscopy to elucidate. In order to increase the lifetime of the charge-separated states, the auxiliary ligand is to be replaced in a further step by a better electron acceptor, for instance with a quinone derivative as terminal acceptor.

\section{Acknowledgements}

We thank the Swiss National Science Foundation and the European Union FP6 - Network of Excellence MAGMANet for financial support.

Received: July 27, 2007

[1] T. Jüstel, H. Nikol, C. Ronda, Angew. Chem., Int. Ed. 1998, 37, 3084.

[2] a) H. Xia, C. Zhang, S. Qui, P. Lu, J. Zhang, Y. Ma, Appl. Phys. Lett. 2004, 84 , 290; b) H. Xia, C. Zhang, S. Qui, P. Lu, F. Shen, J. Zhang, Y. Ma, J. Phys. Chem. B 2004, 108, 3185.

[3] a) M. O. Wolf, C. W. Rogers, Coord. Chem. Rev. 2002, 233, 341; b) M. Bendikov. F. Wudl, D. F. Perepichka, Chem. Rev. 2004, 104, 4891.

[4] a) M. Grätzel, Inorg. Chem. 2005, 44, 6841 ; b) D. Gust, T. A. Moore, A. L. Moore, Acc. Chem. Res. 2001, 34, 40; c) M. Grätzel, Nature 2001, 414, 338.

[5] a) E. Krausz, L. J. Hughes, P. Smith, R. Pace, S. Peterson, Photochem. and Photobiol. Sci. 2005, 4, 744; b) L. M. Yoder, A. G. Cole, R. J. Sension, Photosynt. Res. 2002, 72, 147.

[6] a) M. Di Valentin, A. Bisol, G. Agostini, P. A. Liddell, G Kodis, A. L. Moore, T. A. Moore, D. Gust, D. Carbonera, J. Phys. Chem. B 2005, 109, 14401; b) H. Imahori, D. M. Guldi, K. Tamaki, Y. Yoshida, C. Luo, Y. Sakata, S. Fukuzumi, J. Amer
Chem. Soc. 2001, 123, 6617; c) M. Grätzel, J.-E. Moser, in 'Electron Transfer in Chemistry 5', Ed. V. Balzani, Wiley-VCH, Weinheim 2001, p. 589; d) G. Kodis, P. A. Liddel, L. de la Garza, A. L. Moore, T. A. Moore, D. Gust, J. Mat. Chem. 2002, 12, 2100.

[7] J. Yamada, T. Sugimoto, 'TTF Chemistry: Fundamentals and Applications of Tetrathiafulvalene', Springer, Berlin, 2004.

[8] R. L. Carroll, C. B. Gorman, Angew. Chem. 2002, 114, 4556; Angew. Chem., Int. Ed. 2002, 41, 4378.

[9] a) T. Otsubo, K. Takimiya, Bull. Chem. Soc. Jpn. 2004, 77, 43; b) U. Geiser, A. M. Kini, J. A. Schlueter, H. H. Wang, J. M. Williams, Mol. Cryst. Liq. Cryst 2002, 380, 29; c) R. Samina, S. S. Turner, P. Day, J. A. K. Howard, P. Guionneau, E. J. L. McInnes, F. E. Mabbs, R. J. H. Clark, S. Firth, T. Biggs, J. Mat. Chem. 2001, 11, 2095; d) P. Cassoux, Coord. Chem. Rev. 1999, 185-186, 213; d) L. Martin, S. S. Turner, P. Day, P. Guionneau, J. A. K. Howard, D. E. Hibbs, M. E. Light, M. B. Hursthouse, M. Uruichi, K. Yakushi, Inorg. Chem. 2001, 40, 1363; e) J. A. Schlueter, U. Geiser, A. M. Kini, H. H. Wang, J. M. Williams, D. Naumann, T. Roy, B. Hoge, R. Eujen, Coord. Chem. Rev. 1999, 190-192, 781.

[10] a) C. Loosli, C. Jia, S.-X. Liu, M. Haas, M. Dias, E. Levillain, A. Neels, G. Labat, A. Hauser, S. Decurtins, J. Org. Chem. 2005, 70, 4988; b) M. A. Herranz, N. Martin, L. Sanchez, C. Seoane, D. M. Guldi, J. Organometallic Chem. 2000, 599, 2.

[11] a) G. J. Meyer, Inorg. Chem. 2005, 44, 6852; b) M. K. Nazeeruddin, S. M. Zekeeruddin, J.-J. Lagref, P. Liska, P. Comte, C. Barolo, G. Viscardi, K. Schenk, M. Grätzel, Coord. Chem. Rev. 2004, 248, 1317.

[12] a) S. Campagna, S. Serroni, F. Puntoriero, F. Loiseau, L. De Cola, C. J. Cleverlaan, J. Becher, A. P. Sorensen, P. Hascoat, N. Thorup, Chem. Eur. J. 2002, 8, 4461; b) F. Voegtle, M. Plevoets, M. Nieger, G. C. Azzellini, A. Credi, L. De Cola, V. De Marchis, M. Venturi, V. Balzani, J. Am. Chem. Soc. 1999, 121, 26.

[13] C. Jia, S.-X. Liu, C. Tanner, C. Leiggener, L. Sanguinet, E. Levillain, S. Leutwyler, A. Hauser, S. Decurtins, Chem. Eur. J. 2007, 13, 3804.

[14] C. Goze, C. Leiggener, S.-X. Liu, L. Sanguinet, E. Levillain, A. Hauser, S. Decurtins, ChemPhysChem, in press.

[15] R. M. Hartshorn, J. K. Barton, J. Am. Chem. Soc. 1992, 114, 5919. 